\title{
Una visión histórica del marro a través de los textos. Entre la actividad lúdica libre y recreativa del marro y su uso como instrumento pedagógico
}

\section{A historical vision of prisioner's bar through the texts. Between recreational freedom and pedagogical control}

\author{
Jordi Brasó $^{1}$, Xavier Torrebadella ${ }^{2}$ \\ ${ }^{1}$ Universidad de Barcelona jbrasorius@ub.edu \\ ${ }^{2}$ Universidad Autónoma de Barcelona xtorreba@gmail.com
}

Recibido: $24 / 7 / 2020$

Aceptado: 23/3/2021

\section{Copyright $($ )}

Facultad de CC. de la Educación y Deporte. Universidad de Vigo

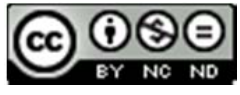

Dirección de contacto:

Jordi Brasó

Edifici Llevant, Despacho 332

Campus Mundet, Universitat de Barcelona

Passeig Mundet, 08035 Barcelona

\begin{abstract}
Resumen
A lo largo de la historia de la educación los adultos han utilizado los juegos corporales como significativos elementos para una re-creación pedagógica. Pero además estos juegos fueron practicados de forma libre en calles y plazas, sin vigilancia, por parte de los jóvenes, hecho que comportaba peleas, gritos, molestar a los transeúntes... Con una idea para controlar la conducta de los pequeños, fue en el siglo XIX cuando estas prácticas entraron en el marco socializador de la escolarización, y juegos como el del marro, en España y en otros países del entorno europeo, experimentaron un proceso de pedagogización. Es a partir del juego del marro que indagamos sobre el proceso de configuración pedagógica del juego motor escolar. Para ello se ha revisado una documentación histórica entre principios del siglo XIX y principios del siglo XX. A modo de conclusión se reflexiona sobre la necesidad de recabar información histórica-social sobre los juegos corporales en la edad escolar y la trascendencia que conlleva el educar para la libertad.
\end{abstract}

\section{Palabras clave}

Juegos Corporales, Historia de la Educación, Educación Física, Pedagogía 
documentation between the beginning of the 19th century and the beginning of the 20 th century has been reviewed. By way of conclusion, the need to collect historicalsocial information about body games at school age and the importance of educating for freedom is reflected.

\section{Key Words}

Body Games, History of Education, Physical Education, Pedagogy

\section{INTRODUCCIÓN}

En España la popularidad del juego infantil se encuentra descrita en una significativa representación de libros de juegos y de gimnástica escolar (Brasó y Torrebadella, 2015b). Uno de los juegos más emblemáticos es el marro (o rescate) que, además es citado frecuentemente en los textos de literatura que evocan memorias de la infancia. Este juego tradicional, cuya presencia histórica se pierde en los confines de los tiempos, ha quedado completamente olvidado al entrar en el segundo milenio (Brasó y Torrebadella, 2016). El marro es el juego de la disciplina, de la estrategia y la dominación; es un juego de complicidades en donde la sagacidad y agilidad de los que participan son elementos determinantes para la victoria.

Si bien ya hay trabajos que estudian y profundizan en las entrañas del juego del marro (Brasó y Torrebadella, 2014, 2015b, 2015c, 2017b, 2018a, 2019a), todavía se pueden aportar más datos significativos que ayuden a interpretar aspectos concernientes a la lógica externa y a las vivencias personales de cada época.

El objetivo de este trabajo es el de contribuir a configurar el marco lúdicopedagógico del juego del marro en España y sostener a partir de él los dominios de saber/poder que subyacen en su lógica externa (Brasó y Torrebadella, 2018c). Asimismo, hay que sostener que las particularidades pedagógicas del juego también pueden ser extrapoladas en el ámbito europeo y latinoamericano. Con todo ello, además, se contribuye a evitar una desmemoria histórica cada vez más presente en la sociedad de hoy en día (Brasó y Torrebadella, 2018b, 2020).

La metodología ha partido de la revisión de los recientes estudios aportados por los profesores Brasó y Torrebadella, pero también de una nueva revisión bibliográfica histórica de carácter inédito, que sustenta una mejor interpretación sobre la realidad del juego durante el siglo XIX y principios del siglo XX. Se ha centrado la atención en el análisis e interpretación de relatos y textos de fuentes primarias en torno al juego. Estos se han contextualizado con fuentes secundarias, y todo ello ha comportado un análisis hermenéutico.

Los resultados muestran una dualidad del juego de marro, teniendo en cuenta el momento en el que se practicaba. De este modo significó un modo de libertad recreativa cuando el juego aparecía de forma libre, sin ningún control por parte del adulto y, una manera de control disciplinario, cuando el juego se practicaba en entornos escolares y los docentes vigilaban las acciones del juego. 


\section{EL JUEGO DEL MARRO EN LA LIBERTAD RECREATIVA DE LA INFANCIA}

Entre los muchos juegos populares del siglo XIX había aquellos cuya tradición se remonta a tiempos ancestrales y que ni tan siquiera la memoria colectiva ha podido precisar (Andújar y Brasó, 2017; Brasó y Collell, 2016; Brasó y Torrebadella, 2015a, 2019b). Así, por ejemplo, al citar aquellos juegos de uso habitual entre los niños de las clases populares de Barcelona que se apropiaban de las calles y plazas de una ciudad intramuros, unos juegos que tanto molestaban a los transeúntes y a la "gente bien", aparece el juego del marro. Este juego también llamado rescate, aunque no era explícitamente un juego prohibido por los bandos municipales (Ayuntamiento de Barcelona, 1857), era uno de los que podía acabar en embarazosas discusiones, inclusive a puñetazos o a pedradas; sin duda alguna, se trataba de una demostración de la hombría, imponiendo la ley del más violento o del más fuerte:

"El domingo-Paseo Nuevo: El domingo último en el paseo de S. Juan o Nuevo hubo una especie de motín como diría el Heraldo y algún otro diario de su color. Estaban jugando al Rescat (rescate) una multitud de jóvenes en frente el cuartel de San Agustín, y esto nada tenía de particular pues es un juego muy divertido; mas después pasó la cosa á vías de hecho, pues los combatientes se incomodaron y se dieron tan lindos puñetazo, arañazos y mojicones que por fin la emprendieron á pedradas unos con otros" (Pujadas, 1848, p. 1).

En esta línea, también, José Fernando de Larra, biznieto del literato Mariano José de Larra, escribía que en el Madrid del "año del hambre" -en 1811-: "En la calle, los chicuelos habían hecho las paces -sus rencores son menos duraderos que los de los hombres- y jugaban al marro con otros personajes tan graves como ellos" (De Larra, 1944, p. 10). Por lo tanto, las calles de estas ciudades eran verdaderamente para los niños un campo de recreo, pero también de luchas. Eran lugares en los que estos no solamente compartían amistades con sus semejantes, también libraban sus disputas en las que aprendían a sobrevivir. Así quedaba reflejado en una crónica de Alberto Serra Guixà (1873-1912), el redactor deportivo de La Vanguardia de Barcelona, que por aquel entonces era uno de los más influyentes propagandistas de la educación física:

"Basta haber atravesado alguno de estos días de invierno claros, frios cuanto secos y salutiferos, dicha plaza de Cataluña, y hasta me atreveré a decir, haber sufrido los efectos de las naturales travesuras infantiles en forma de pelotazo, carga u otra cosa semejante, para quedar plenamente convencido del desahogo y expansión al aire libre que reclaman a voces aquellas agrupaciones de parvulitos, que unos a foot-ball, otros a combas, al marro o al escondite los de más allá, hacen inocente e inofensivo acopio del oxígeno, que raramente encuentran en sus habitaciones, poco ventiladas y peor caldeadas por el astro del día, en esa edad en que el cuerpo necesita imperiosamente del ejercicio al aire libre, con objeto de activar y promover la circulación sanguínea" (Serra, 1905, p. 1).

La literatura de la Condesa de Genlis $(1842,1864)$-Stéphanie Félicité du Crest de Saint-Aubin (1746-1830)- puso en escena este juego, que tan popular era también en Francia (Amar y Jauffret, 1803; Dillaye, 1885; Le Prince, 1822; Vergnaud, 1831) (Figura 1). En Las veladas de la quinta: novelas e historias morales para que las madres de familia puedan instruir a sus hijos juntando la doctrina con el recreo, uno de los protagonistas, el joven César, demostró en el juego del marro sus principales virtudes físicas -agilidad, habilidad, destreza- y morales -valor y libertad-: 
“Como era César más ágil y robusto de lo que se podía esperar de su edad, lució muchísimo en este juego, porque sus lances proporcionan la ocasión de manifestar ligereza en alcanzar a los contrarios; habilidad y maña engañando al que persigue; buena fe condenándose a si propio en los lances dudosos; y finalmente, valor y generosidad, exponiendo su libertad para darla a los prisioneros de su bando” (De Genlis, 1864, p. 150).
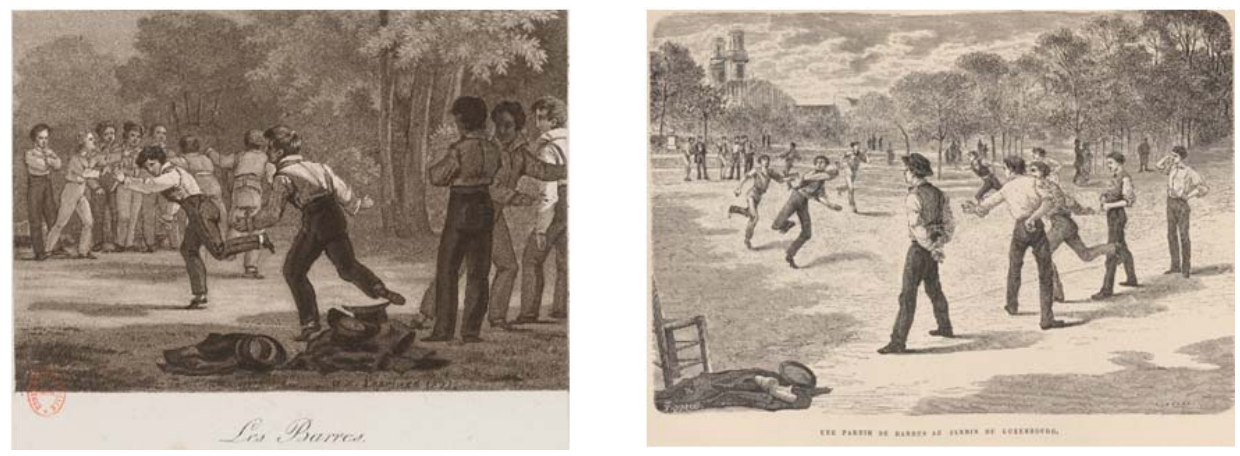

Figura 1. Les jeux des jeunes garçons (Le Prince, 1822) y Les jeux de la jeunesse (Dillaye, 1885)

Así, aparecía el juego fuera del tiempo escolar, es decir, sin la vigilancia y el orden. Este es precisamente el gran poder de atracción que tenía el juego del marro, el que también permitía y se deseaba jugar preferentemente a extramuros escolares. Era pues, en esta condición, que el juego, sin el control del adulto, podía llegar a su máxima expresión de realidad, proporcionando a los participantes un aprendizaje de disciplina, obediencia y sumisión entre iguales, al respetar las reglas (pactadas) del juego y, también, los códigos simbólicos entre las relaciones de complicidad y de saber/poder que se desprendían de las relaciones interpersonales.

Por lo tanto, este juego tiene una condición importante: es un juego de bandos, un juego de confrontación y socialización. $Y$ en él aparecen diferentes roles y liderazgos de modo natural entre los componentes de los equipos como ya sucedió en Grecia con Aquiles, Ulises y los diferentes héroes descritos por Homero, o también en la aparición del futbol en Inglaterra y la creación de las Public Schools (Hughes, 1923). Y todo ello iba marcado por una emoción y simbolismo, por ejemplo, en las disputas: los de la calle de arriba contra los de la calle de abajo, los de un barrio contra el otro. Destaca también la finalización de la práctica que es simplemente cuando lo decidía el grupo.

El mismo Santiago Ramón y Cajal (1852-1934) cuenta que, a la edad de ocho años, en Ayerbe -provincia de Huesca-, sintió la atracción por experimentar en los juegos de aquellos muchachos del pueblo, juegos algo muy diferentes a los que él conocía. Ramón y Cajal ya lo decía, en estos juegos se encontraba una preparación del cuerpo y del carácter que hacía del individuo un ser más preparado para soportar las luchas de la vida. Pero hay que destacar que el inocente juego del marro y otros juegos eran censurados y se hallaban en el marco de la desobediencia a la política social, que encarnaba la autoridad de un mundo dominado por el machismo de los adultos. Ahora bien, estas prohibiciones entraban en el juego de la clandestinidad, de las chiquilladas, es decir, de los dispositivos sociales latentes que configuraban el predominio de una sociedad patriarcal y violenta.

"Tienen los juegos gran importancia para la vida de acción y de conocimiento. En estos certámenes de agilidad y de fuerza se demuestran el valor, la osadia, la astucia; se adquieren cualidades del espiritu y se templa y robustece el cuerpo para las luchas de la vida. 
En cuanto se calmó la mala voluntad de los muchachos para conmigo, tomé parte con ellos en los juegos del peón, del tejo y del marro, sin olvidar las carreras, luchas y saltos en competencia. ¡Qué alegría al reconocer que ganaba cada día en energía y flexibilidad! Pero lo malo era que los chicos de Ayerbe no se entregaban sólo a juegos inocentes: el marro y el tejo alternaban con diversiones más bárbaras y pecaminosas. Las pedreas y el asalto a los huertos serán ocupaciones favoritas de los zagalones del pueblo, los cuales tuvieron pronto en mi un discípulo aprovechado.

Yo opuse al principio alguna resistencia a los juegos brutales, así como al escalo de huertos y rebatiña de frutos. Pero el espiritu de imitación pudo más que los sabios consejos de mis padres y los mandamientos del Decálogo. Algo hubo en que no transigí jamás: era el abuso de fuerza con el débil y el ataque injusto o cruel, porque algo del culto a la justicia subsistió siempre en mí, aun en medio de las más disparatadas empresas.

Como yo tenía, comparado con los rústicos chicos de Ayerbe, algunos conocimientos y cierto hábito de discurrir, pronto les aventajé notablemente, así maquinando diabluras como en los juegos y luchas. Gracias a la continua gimnasia, brincaba como un saltamontes, trepaba como un mono, corría como un gamo, escalaba una tapia con la soltura de una lagartija, sin sentir jamás el vértigo de las alturas ni aun en los aleros de los tejados y en la copa de los nogales, y en fin, manejaba el palo, la flecha y, sobre todo, la honda, con mucho tino y maestría” (Ramón y Cajal, 1925, pp. 30-31).

De todas formas, oponiéndose a esta censura destacaban las palabras del Dr. Arsenio Marín Perujo (1854-1903) que arremetía contra aquellos padres de familia, "las gentes de alto tono", los cuales en sus paseos obligaban a permanecer a su lado a sus hijos y "a no detenerse en las plazuelas de los jardines a ver jugar siquiera a otros niños" (Marín Perujo, 1883, p. 119). Esta distinción de clase y de pundonor moral, no solamente condenaba a los niños a la inmovilidad y la flojedad física, sino también a marcar un carácter retraído y pusilánime. Por eso aconsejaba a las madres, que también educaran para lograr niños revoltosos, los cuales, luego se convertirían en hombres fuertes y robustos de cuerpo y también de espíritu:

"Salgan, pues, los niños a los paseos y plazas; únanse a otros compañeros (de su misma edad, esto es lo principal) que conocen o no; traben polémicas y conversaciones; organicen al momento el juego, la gimnasia sin aparatos; corran de un lado a otro. ¿Entran en amistad? ¿Empiezan con disputas? ¿Se inician riñas? ¿Vuelven a la cordialidad? Dejadles, acostumbradlos a las peripecias de la vida, al ejercicio y las discusiones; vigiladles, sí, a lo lejos, con cierta observación; más no turbéis las asociaciones al aire libre, que tan provechosas son siempre, y que robustecen el cuerpo y la inteligencia de los hombres del porvenir" (Marín Perujo, 1883, p. 119).

A la vez, la invasión colonial del deporte anglosajón provocó una reacción de resistencia patriótica que, inscrita en el discurso regeneracionista, trataba de rescatar y renovar las tradiciones de los juegos considerados como autóctonos (Sport Popular, 1893). Así lo proclamaba el mismo Santiago Alba (1899, p. CX), remarcando que la “reconstitución física y moral de esta raza” también podía llegar de:

"esta gran corriente por el ejercicio físico, contribuyendo a que los bolos, la barra, el paso y el marro, ocupen en domingos y dias festivos las horas que hoy absorben el tute, el mus, el monte y la carteta, y sustituyendo el aire infecto de la tasca por el confortante ambiente del campo" (Alba, 1899, p. CX). 
Y cuando llegó el foot-ball, el marro encontró el virus que, finalmente, le arrebató el entusiasmo como juego (Brasó y Torrebadella, 2015b). Así quedaba recogido en las memorias del médico Carlos María Cortezo (1850-1933):

“mientras los muchachos jugábamos al marro, al paso, al toro y a otros sports que constituían nuestro encanto, como hoy lo constituye el idealismo de la patada y de la coz que, con el nombre de foot ball, nos han regalado nuestros espirituales amigos los ingleses" (Cortezo, 1923, p. 49).

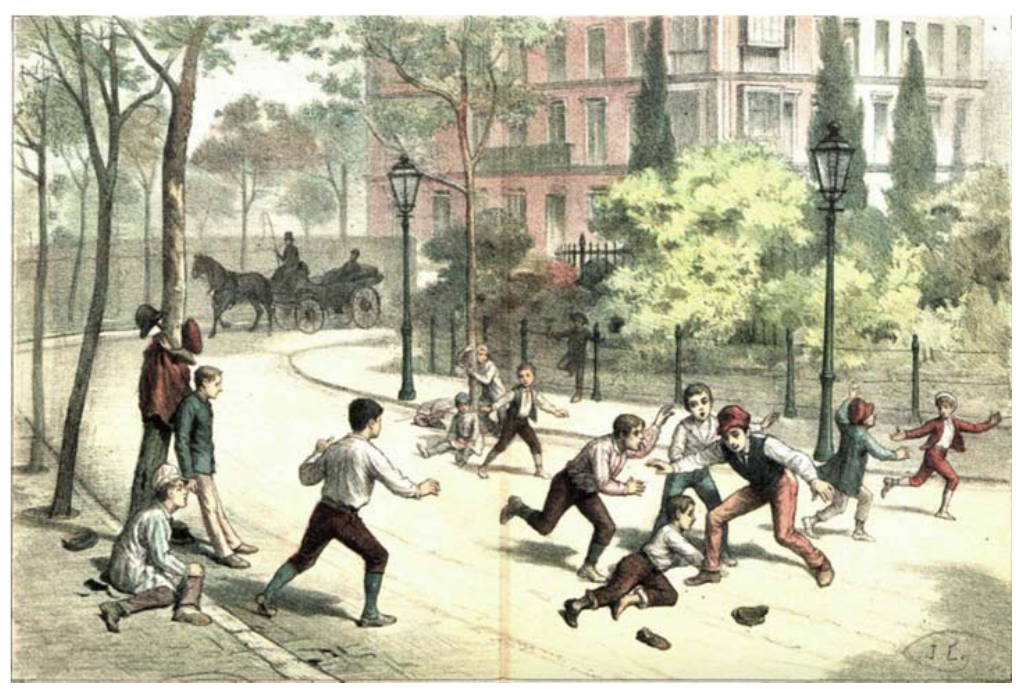

Figura 2. El marro fue uno de los juegos de calle más preferidos por los niños españoles. Fuente: "Marro", El Mundo de los niños, 30 de julio de 1888

Ciertamente, en ciudades como Madrid o Barcelona, la presencia del juego del football en los patios de los colegios y en las plazas iba ganando protagonismo a los juegos tradicionales (Brasó y Torrebadella, 2015b, 2015c) (Figura 2). Incluso sucedía en la ciudad de Buenos Aires, en donde se comentaba que, si bien el rescate continuaba siendo el juego más popular en las escuelas y entre los niños de las calles, ya no era como antes:

"Antiguamente los niños de las escuelas iban a los sitios baldios á jugar al rescate, como van hoy a los prados de foot-ball y ponían en conmoción barrios enteros con sus carreras y con sus risas pues generalmente con éstas era premiado todo jugador cuyas tretas fuesen descubiertas" (Álvarez, 1902, p. 62).

Pero el juego también apareció en otro ámbito, el escolar, ya fuese en el recreo o como elemento de la gimnástica; y en este entorno no tenía el mismo significado que fuera de él. Porque "en el colegio todo es emulación, y el que no es el primero en el tema, quiere ser al menos el primero en el juego de pelota o en la carrera" (Janet, 1870b, p. 427); y es allí el lugar en donde el niño se prepara verdaderamente para las luchas de la vida, entre sus compañeros amigos y rivales, y aprende el honor a defenderse, adquiere fuerza y se endurece.

La visión negativa del juego libre -incluso vigilado por los padres-, a menudo se veía, por ejemplo, en el hecho de no querer ir a la escuela, o simplemente de estudiar: "¿Cómo lo haréis [padres] para que el niño halle agrade el ir a estudiar su gramática cuando está en el calor de un partido de marro?" (Janet, 1870a, p. 301). Por lo tanto, el momento y lugar de la práctica lúdica determinaban el significado del juego. Queda, como consecuencia, tratar este juego del marro en su lógica externa del entorno 
pedagógico-escolar, un ámbito, por cierto, bien diferente -podríamos decir que antagónico-que el juego libre en la calle.

\section{EL JUEGO DEL MARRO, UN DISPOSITIVO DE ENCIERRO PEDAGÓGICO}

El juego del marro, aunque ya era conocido, llegó a través de la obra del prusiano Johann Christoph Friedrich Guts Muths (1759-1833); en este caso con la versión francesa de Amar y Jauffret (1803). La traducción española se conoció con el nombre La gimnástica o escuela de la juventud (1807). Sin embargo, el juego se tradujo por el de "Moros y Cristianos" (Figura 3), una alusión que reflejaba el carácter religioso y castrense con el que se quería impregnar el libro, puesto que estaba dedicado al Real Seminario de Nobles de Madrid (Llorens y Torrebadella-Flix, 2017).

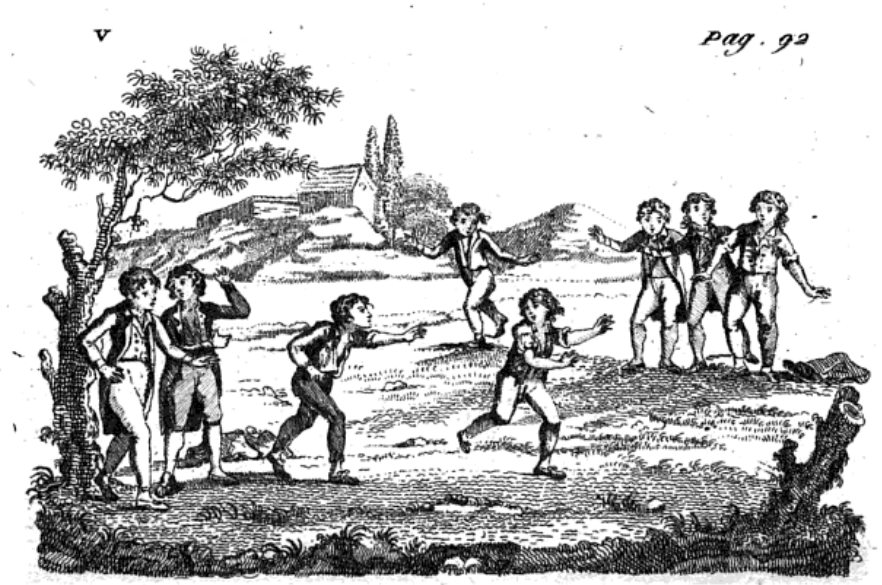

Figura 3. Grabado del juego "les barres" (Amar y Jauffret, 1803)

Pero también, el mismo Francisco Amorós y Ondeano (1770-1848) -el catalán de Valencia exiliado en Francia-, reconocido por ser el fundador de la educación física en Francia, lo recomendó en su obra póstuma, Nouveau manuel d'éducation physique, gymnastique et morale (1848). Así mencionaba que juegos corporales como el de la honda o el marro, y otros tantos muy conocidos, por su naturaleza ya formaban parte aceptada en la gimnástica (Figura 4).

La fronde. Cet exercice consiste à enfermer une pierre ou une balle de plomb dans le pli aplati à dessein d'une corde dont on tient les deux bouts; elle reçoit, d'un mouvement de circonduction qu'on lui imprime, un degré de vitesse qui augmente la force de celni qui se sert de cet instrument. L'objet de ce mouvement est de diriger avec succès la pierre vers le but qu'on veut atteindre.

Les autres exercices et jeux gymnastiques de la bascule, des barres, du palet, des quilles, des vélocipédes, etc.,, sont si connus qu'il 'est inutile d'en parler. (Voyez le Manuel des Jeunes gens de l'Encyclopédie-Roret ).

Figura 4. Nouveau manuel d'éducation physique, gymnastique et morale (Amorós, 1848, p. 384) 
En España, a lo largo del siglo XIX, el juego del marro como muchos otros juegos de niños y niñas sufrieron un proceso de pedagogización, de sociabilización y, si se desea mencionar, de civilización y control (Elschenrboich, 1979). En buena medida, la progresiva entrada de la educación física en el mundo escolar marcó el destino de muchos de estos juegos (Amar y Jauffret, 1803) (Figura 3). De aquí que, también, estos juegos fuesen recogidos en manuales a propósito de orientar la moralidad de los niños y niñas (López Villabrille, 1855). Ya el mismo Vicente Naharro Grima (1750-1823), maestro de primeras letras, entendió el proceso moralizador y educativo del juego, tan eficaz para aprender las primeras letras (Naharro, 1818). De este modo, a través de los juegos, despertó el interés de los niños para aprender a leer y moralizar conductas (Torrebadella, 2011).

Y este proceso de pedagogización, de sociabilización o de civilización quedaba muy bien expresado por Santiago Arnal Ramos, Inspector de Primera enseñanza de Navarra:

“A las personas encargadas de su educación les corresponde, pues, iniciar á los niños en los juegos buscando, entre los que de antiguo se conocen y otros que pueden inventar, aquellos que tengan mayor atractivo, que no sean molestos, ofensivos ni pesados y que respondan á un fin pedagógico, sin que los mismos niños se aperciban, por supuesto, de este carácter educativo que al juego se le trata de imprimir" (Arnal, 1893, p. 98).

Una característica del juego del marro, y que es clave para entender la pedagogización del juego, es el fundamento del dispositivo de captura, es decir, aquel instinto básico y depredador de la filogénesis: alcanzar a la presa, capturarla y poseerla de algún modo para un fin determinado. Por lo tanto, el cazar y ser cazado entran en las primeras formas lúdicas de la infancia. Y es aquí cuando se expresan dos formas de correr -elementos claves de la lógica interna del juego (Torrebadella y Brasó, 2014)-, una relacionada con la depredación y, la otra, relacionada con la escapatoria de la primera. No obstante, ambas formas son esenciales para la supervivencia (Brasó y Torrebadella, 2019a) (Figura 5). Y estos dispositivos de captura son re-creados en la edad adulta, en la sociedad, y entraron a configurar un espacio simbólico también en el proceso de deportivización. Así, este proceso, que es propio del proceso de civilización, redujo la crueldad y peligro de las capturas y de las cacerías y llegó a convertir las crueldades de los juegos más atávicos en el ocio (Sánchez-Crespo, 2010) y, en definitiva, en los deportes modernos (Elias y Dunning, 1992). Podríamos decir, por lo tanto, que tanto la deportivización como la pedagogización lúdica implican una regulación, un control, una disciplina de la acción motriz. El juego así se civiliza acorde a diferentes normativas, reglas y modos considerados óptimos y correctos de la sociedad de cada época y lugar. Así, para el caso que nos ocupa del marro, la libertad que había en el juego libre o incluso en excursiones y recreos escolares, era antagónica al control en la escuela, con un juego organizado.

Toda esta práctica lúdica escolar permitía trivializar la guerra, de igual modo que en otros juegos de bandos se simulaban combates, se hacían prisioneros y se mandaban fusilamientos. Estas actividades, en palabras de José Francos Rodríguez (1862-1931), endurecen los corazones de los niños y preparan a estos para las decisiones que en el futuro tendrán que tomar como adultos (Francos, 1883). Se visualiza aquí una voluntad por conseguir que los jóvenes adquirieran un pensamiento lacedemonio, de lucha y de entrenamiento para afrontar y desafiar a los enemigos (Brasó, 2018; Brasó y Garcia, 2019). 
No obstante, este juego tan excitante -y otros parecidos- incitaban a los jóvenes el hacer novillos -librándose eventualmente de la cárcel escolar- para poder jugar, y ello, también, les podía conducir a la mala vida callejera. Así, para remediar este peligro, algunos de los padres tomaban la decisión de encerrar a sus hijos de aprendices en un taller. Era una embarazosa situación que castigaba a los niños a una esclavitud de por vida. De tal modo lo exponía el Dr. Luis Vega-Rey (1853-1899), crítico conocedor de la vergonzante miseria humana - pobreza y mendicidad- que manchaba la opulencia de las clases acomodadas de la capital de España (Vega-Rey, 1885). Se visualiza aquí el castigo ante la falta de disciplina:

“-Quiero que me sujete Ud. a este bribón para que aprenda a ganarse el pan, porque, si no, acabará en un presidio.

Al pobre Nino se le saltan las lágrimas al oir estas palabras de aquel que le diera el ser, porque la criatura no ha cometido falta mayor que no ir a la escuela, incitado por chicuelos de su edad para jugar á la toña o al marro" (Vega-Rey, 1884, p. 104).

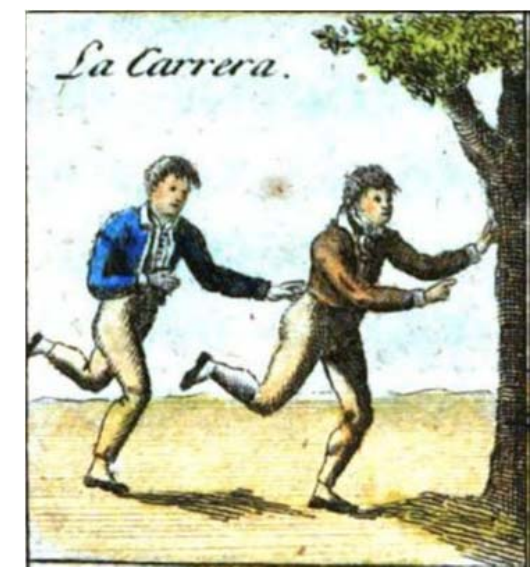

Figura 5. Descripción de los juegos de infancia (Naharro, 1818)

Este juego fue descrito en muchos tratados y su relato técnico estaba repleto del lenguaje bélico el cual connaturaliza la trivialización de la guerra (Brasó y Torrebadella, 2019a). Así, en el inocente juego de niños subyacía una legendaria violencia que entraba a conformar el carácter de la llamada moderna masculinidad. Esta masculinidad venía pues caracterizada por la valentía, el arrojo, la temeridad o la astucia en el combate que se expresaban en el héroe (Brasó y García, 2019). A modo de ejemplo, véanse las detalladas explicaciones de su práctica en una de estas obras:

"Marro. Para este juego se necesita un gran espacio llano, donde puedan moverse con holgura los combatientes. Reúnense éstos en dos grupos, compuestos del mismo número y obedeciendo cada cual a su jefe, que es el que dirige los movimientos. El espacio ocupado por cada grupo se marca en los extremos del sitio, donde se haya de efectuar el juego, por una línea de tres o cuatro metros de longitud, y a una distancia de tres o cuatro de un árbol, de un kiosco o de una pared cualquiera.

Puestos en fila, frente a frente, uno y otro bando, en su campo respectivo, y echadas ya suertes sobre cuál de los dos ha de principiar la batalla, uno de los jugadores del partido designado por la suerte sale de su campo, se acerca al enemigo y se coloca extendiendo un brazo delante del adversario, provocándole de esta manera. El provocado le alarga una 
mano y entonces el otro le da tres golpes seguidos, huyendo inmediatamente a su campo, púes el que recibió los golpes habrá ya salido en su persecución, procurando cogerlo o sólo tocarlo para hacerlo prisionero. En auxilio del fugitivo sale ahora un nuevo combatiente á fin de coger al perseguidor, y así se generaliza la lucha. Pierde marro o es marro todo jugador que haya salido después de otro; el que no tiene marro necesita entrar en su campo para tomarlo, y, saliendo de nuevo, poder atacar al contrario. Si consigue alcanzarlo, grita cogido y se lo lleva preso a su campo. Después de una breve pausa, en que reciben los vencedores al prisionero, vuelve á trabarse el combate.

Distinguense varias clases de marro, según el modo de conducirse los vencedores con los vencidos. Unas veces son devueltos, y en este caso el juego consiste en hacer un número determinado de capturas, ganando el grupo que antes las realiza. Otras, se quedan en rehenes, que hay que rescatar o canjear por un número igual en el bando contrario. Si vienen nuevos prisioneros a juntarse con el primero, se pondrán todos en una fila, en el costado, la cadena, cogidos de las manos y ocupando el mayor espacio posible, para hacer fácil a alguno de sus camaradas tocar al último de aquéllos y efectuar así el rescate de todos. Es claro, que los guardianes vigilarán por que esto no suceda, oponiéndose a las estratagemas de los libertadores. El empeño de unos y otros señala el punto culminante de la contienda.

Terminase el juego cuando uno de los partillos ha sufrido pérdidas tales que ya no abriga esperanzas de libertar a sus compañeros. Si los bandos tienen prisioneros, entonces pueden canjearlos en número igual, guardando el sobrante el que lo tenga.

Llámase marro forzado aquella clase del juego que nos ocupa, en que se quedan los prisioneros como combatientes en el bando que los ha apresado; de modo, que el juego viene a terminarse, o porque todos los combatientes queden en un solo campo, o porque el contrario, después de haber sufrido grandes pérdidas, renuncie a seguir peleando" (Un aficionado, 1903, pp. 246-247).

La significación constructivista y también autotélica del marro ha posibilitado que las escenas del juego quedasen impresas en algunas obras literarias que testimonian su popularidad histórica. Aparte, la aceptación social del juego quedó reafirmada, tanto en los manuales de educación física como en los repertorios de juegos populares (Figuras 6 y 7).

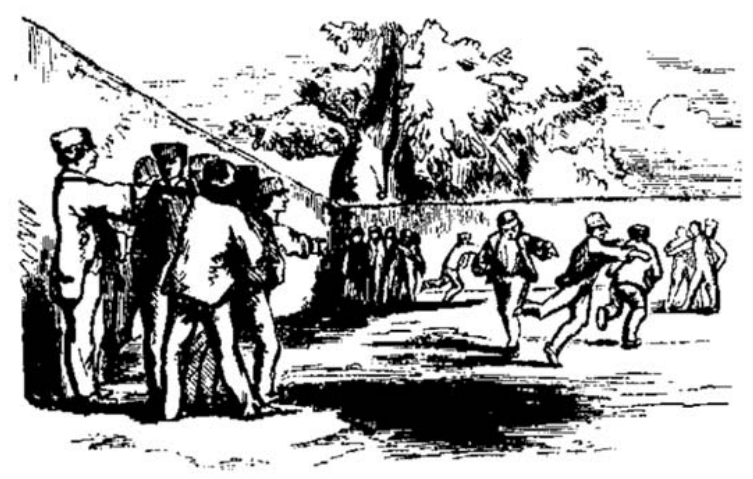

El marro.

Figura 6. Juego del marro entre los muros de un colegio internado. Repertorio completo de todos los juegos (De Marco y Ochoa, 1896) 


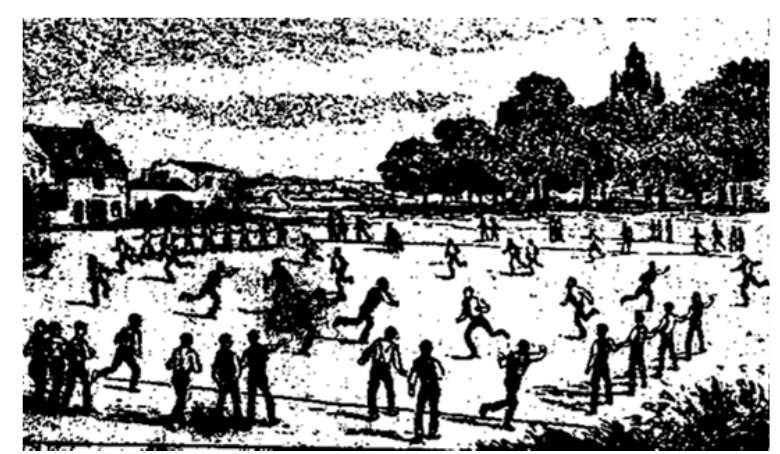

Figura 7. El Marro: “Aspecto de una jugada”. Tratado racional de gimnástica y de los ejercicios y juegos corporales (García Fraguas, 1896)

También se cita el marro en el Colegio de San Antón de los Padres Escolapios en Madrid, donde los niños salían siempre los jueves y los domingos para jugar (Jueves y Domingos, 1874). Otras referencias se encuentran en el Romance de Manuel Ossorio Bernard, director de la revista El Mundo de los Niños (Ossorio, 1888), y en el bonito grabado de una escena del juego en plena calle, eso sí, siempre con el posible enojo de los transeúntes (Figura 2). Así, la pasión por este juego era refrescada de generación en generación y difícilmente un niño podía pasar su infancia sin haber tanteado siquiera la posibilidad de jugar (Pereda, 1880, 1888). De tal modo lo recordaba el poeta, dramaturgo y periodista Carlos Luis de Cuenca y Velasco (1849-1927), que en sus tiempos de juventud el juego del marro era practicado -también como indicaba Ramón y Cajal (1925) al hablar de su infancia- tanto por los niños de primeras letras, como por los muchachos más grandullones de la facultad, reuniéndose todos en el patio de la leonera vieja del Buen Retiro (Madrid). Además, destacaba la simpática y divertida emoción del lance de rescatar a los prisioneros:

"El secreto de aquel lance consistía, en sentir de los más prácticos, no tanto en la habilidad del que se emboscaba, para llegar por ocultos caminos a tocar las manos de los cautivos que en el marro contrario guardaban anhelantes su redención, sino en el arranque del que a la vista de todos lanzábase de repente y por derecho con tal ímpetu, que cuando los contrarios llegaban a detenerle ya habia lanzado aquel entusiástico grito, que me parece estar oyendo: Rescatao!!” (Cuenca, 1901, p. 3).

El interés cada vez mayor por la calidad de vida de la infancia, a causa de: la insuficiencia higiénica, las malas condiciones de vida y habitabilidad -poca luz, poca ventilación, suciedad...- y, como consecuencia, la alta mortalidad infantil fueron motivos para potenciar las prácticas corporales en la naturaleza y el juego del marro a inicios del s. XX (Brasó, 2018a). Incluso algunos colegios, para compensar el hecho de no tener un buen gimnasio, adoptan "juegos y entretenimientos viriles, que, debidamente vigilados, suplen tal deficiencia" (Llaverías, 1904, p. 684). Naturalmente, el juego del marro fue incorporado, sobre todo, en tanto que lo permitían los paseos escolares al campo (Arnal, 1897), aprovechando aquella explanada en que se podía practicar sin peligro alguno de molestar a los transeúntes (Brasó y Torrebadella, 2015c): "El marro, y en general, todos los juegos en que intervienen dos partidos se recomiendan para los niños por la destreza que necesitan en su ejecución y el atractivo que origina la lucha" (Arnal, 1893, p. 98; 1897, p. 74). Por lo tanto, el marro cumplía funciones higiénico-médicas, pero también de preparación y simbolismo bélico. En esta idea, como trataba Bailly-Balliere (1912, p. 413; 1918, p. 341), es cierto que "este juego 
exige gran vivacidad, sangre fría y golpe de vista y habilidad, es un juego de correr de los más sencillos y divertidos”, pero también su inocencia ponía en juego una figuración bélica moralmente aceptada por la sociedad del momento. Esto sucedía cuando el fútbol y los batallones infantiles configuraban la esencia de una educación física escolar y cuyo principal objetivo, sobre la coyuntura de un marco regeneracionista, era el de virilizar a los jóvenes o, dicho de otro modo, militarizar la educación física escolar (Torrebadella, 2015, 2017).

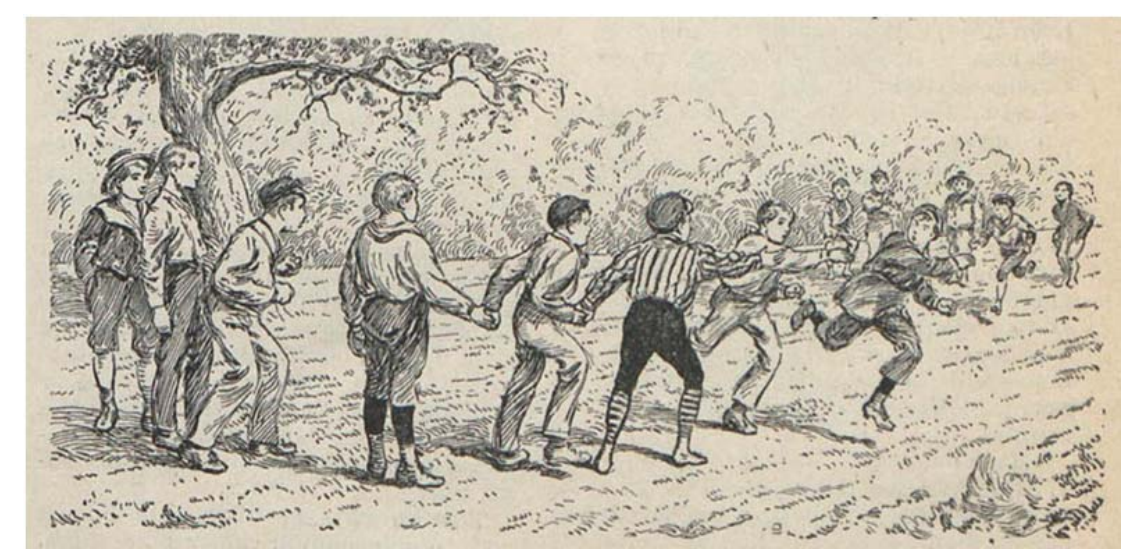

Figura 8. Imagen del juego del marro (Gallach, 1915, p. 37)

La popularización del juego, en una sociedad humilde, con pocos recursos era evidente; el marro cumplía el requisito de ser un juego con pocas necesidades para su práctica -no hacía falta ningún material y se podía jugar en cualquier sitio-. Como mencionaba Gallach (1915), la mayoría de los niños conocían este juego (Figura 8). Así, mientras el mundo luchaba en la sinrazón de la I Guerra Mundial se reproducían, una vez más, sus reglas. Por lo tanto, el juego se prestaba a la simulación fantasiosa de la guerra, de un combate contra un enemigo. El análisis normativo ya permite intuir esta (re)creación bélica:

“A 40 o 50 metros de distancia se trazan dos líneas paralelas, que marcan los campos. Los jugadores se dividen en dos bandos iguales y toman posiciones en sus campos respectivos. Un jugador adelanta hasta cerca de la línea opuesta y llamando a uno del campo enemigo por su nombre, lo desafía. Este corre hacia el provocador, el cual huye. Inmediatamente sale del primer bando otro jugador en socorro del provocador, corriendo hacia el provocado. Este retrocede a su vez, mientras de un bando sale otro compañero en su ayuda, y asi sucesivamente, y de conformidad con las reglas siguientes: $1^{\circ}$-Todo jugador puede hacer prisioneros a los del bando contrario, que hayan salido al juego antes que él; $2{ }^{\circ}$ no se puede apresar a ninguno, sino dentro del campo de juego. Para hacer un prisionero basta tocarlo.

Los prisioneros se guardan en el campo enemigo, cogidos todos de la mano, es decir, formando cadena, que se extiende hacia el campo opuesto. Si un amigo de los prisioneros, a riesgo de caer también él, llega a tocar con la mano al primero de la cadena, toda la cadena queda en libertad.

Esto es lo general, pero el trato de los prisioneros es cosa que se ha de convenir de antemano. Unas veces se acuerda devolverlos inmediatamente, y en este caso gana el bando que ha hecho más capturas. Otro convenio es el de marro forzado, en que cada prisionero va a engrosar el bando enemigo, combatiendo en el campo opuesto, y el partido acaba cuando un bando se queda sin jugadores" (Gallach, 1915, p. 37). 
Ahora bien, después de la I Guerra Mundial se desencadenó el resurgir de unos nuevos nacionalismos, los cuales encontraron en la exaltación deportiva de la juventud una tribuna para educar, visibilizar y rivalizar en los ascensos, que ya desde hacía décadas mantenían las naciones (Torrebadella-Flix y Domínguez, 2018).

Así, si a inicios del s. XX los juegos tradicionales facilitaron que el deporte entrase en los muros escolares para recrear a la juventud y que estos se alternasen con los juegos corporales extranjeros (Torrebadella y Brasó, 2019a), a partir de 1919, el deporte se impuso y el patrón educativo anglosajón irrumpió significativamente en muchas costumbres escolares. De nada sirvieron los llamamientos para advertir de la posible desaparición de los juegos tradicionales, como el del literato Carlos Luis Costa, que detallaba que este "juego español" estaba cayendo en desuso, siendo "difícil encontrar no ya quien lo ejercite, sino quien lo entienda ni lo conozca siquiera" (Cuenca, 1901, p. 3). Quedaba así el deporte colectivo como monopolizador de la práctica escolar:

"De aqui que las naciones más adelantadas haga tiempo que se preocupen del juego, y por ser elemento de tanta vitalidad pongan todas sus miras en extenderlo a las clases sociales, e introduciéndolo en el tesoro de las costumbres patrias, hacerlo popular. El pueblo inglés, el más práctico de los europeos, ha dado al juego la consagración de institución nacional, y hase visto a alemanes y franceses, hollando antagonismos y rivalidades de raza, pasar el Estrecho y hacerse sus discípulos en este punto, los que a su vez, instruidos singularmente en los juegos llamados colectivos, los más pedagógicos y morales, volverse a sus paises y dar conferencias y cursos populares, cual si volvieran del Nuevo Mundo en el siglo de los descubrimientos" (Rodríguez, 1919, p. 684).

En este nuevo marco de transformación educativa y social se manifestó el reverendo Bruno Rodríguez del colegio internado de las Escuelas Pías de Sarrià y señaló el valor social y moral de los juegos corporales. Sobre los juegos para los grados superiores mencionó lo siguiente:

"Juegos de los grados superiores. - Esta edad requiere ejercicios de mayor habilidad, esfuerzo e interés; cuanto más se ríen los niños de la sencillez y ridiculez de los pequeños, más ingenio y destreza alardean ellos. Por eso en los años de diez a quince, en que tiende el niño a la singularidad y arrogancia personal, debe cuidar el maestro de atraerlos a la concertación colectiva, ensenándoles juegos que requieran la unión y solidaridad; tales como algunos del grado anterior, el marro, (...)

Aqui si que recomendaríamos que el maestro interviniese para sostener mejor la animación, evitar las murmuraciones y expresiones soeces que a veces se les escapan a los más bravucones, no menos que las conspiraciones que suelen urdir los descontentos y orgullosos de los colegios. Debe compelerse a jugar a los que se retraen por no saber, pues la cobardía de ahora apoca cada vez más en los años sucesivos y los vuelve huraños y misántropos por ser incapaces de intervenir en lo que los compañeros muestran agilidad y destreza. No dejan de ofrecer algún peligro ciertos juegos de esta edad, como el marro o rescate, la calva, barra, pasábalo y casi todos los sistemas de pelota extranjeros; pero la sabia dirección del maestro puede evitar los casos más peligrosos, pues en compensación envuelven ventajas de colectividad insubstituibles para esta edad, y he aqui una nueva razón de preferencia del colegio sobre la familia, donde no pueden jugar más que los rapaces, y tienen que irse los mayores a la calle o rendirse a la seducción morbosa de las novelas" (Rodríguez, 1919, p. 690). 
Destaca también en el juego del marro la práctica en las niñas. A menudo, ellas podían jugar. Aprendían, de manera simbólica, el dispositivo viril de la captura de las mujeres, de dominar y ser dominadas, pero también el placer de desobedecer y practicar un juego que estaba reservado al sexo masculino; un juego de esfuerzo y de ingenio, pero en el que alguna de las niñas podía manifestar su diferencia o singularidad respecto a las características tradicionales atribuidas a su sexo. Así se expresó Concepción Arenal (1820-1893), en el Congreso Pedagógico Hispano-Portugués-Americano celebrado en Madrid un año antes de su muerte:

"Si una niña que conserva aún el instinto de conservación quiere ejercitar sus músculos con alguna energía, se la reprende diciéndole que esos juegos son de muchachos; las niñas han de jugar de modo que no se rompan el vestido (tan fácil de romper), ni se despeinen, etc. (Arenal, 1892, p. 312).

Aparte, en las niñas se tenía la costumbre que, al llegar estas a la edad de los siete años, se las separase de los juegos entre sexos. De este modo, las niñas ya iniciaban el proceso doméstico de encarcelamiento (Brasó, 2016), mientras sus hermanos podían jugar en los alrededores de la casa, ellas, las pobres, quedaban confinadas en el interior:

"Hay juegos que son únicamente propios de muchachos como la pelota el rehilete, la peonza, echar carreras, para las cuales se necesita cierta agilidad que contribuye al desarrollo de las fuerzas fisicas. Las niñas se mezclan a veces con sus hermanos o parientes en tales entretenimientos; pero no debe permitírseles jugar juntos cuando lleguen a edad de siete años, por la diferencia que hay entre la fuerza física de ambos sexos, y porque los muchachos no tienen bastante conocimiento para hacer esta diferencia: asi que puede ser perjudicial a las niñas lo que es útil a los muchachos" (Campan, 1845, pp. 94-95).

Efectivamente, en el seno de la educación burguesa las limitaciones del juego libre y espontáneo tenían en las niñas una larga tradición. Estas no podían ejercitarse y divertirse como los niños de su misma edad. De aquí que todo juego como el del marro suponía para las niñas un higiénico y agradecido ejercicio físico. De todas formas, y eso era lo más importante, el juego del marro se veía como un ejercicio que recompensaba las tradicionales tareas sedentarias de las niñas, lo cual contribuía a reducir los riesgos que afectaban a la fecundación:

"Una educación afeminada o sedentaria infaliblemente debilita la mejor constitución natural; y si los muchachos se crían con la misma delicadeza que las niñas, nunca podrán llegar a ser hombres. A los niños, no solo se les ha de dejar correr y brincar moderadamente ciertas horas del día, sino que debe incitárseles a ello.

No es la crianza de las hembras menos dañosa a su constitución que la de los varones: la niña se ocupa en su presunción antes que sepa vestirse, y se le enseña que el uso perfecto de la aguja es la única cosa que puede granjearle la estimación de todos.

Indudablemente que la laboriosidad es una de las prendas más estimables de la mujer; pero sería inútil que nos detuviéramos en demostrar las peligrosas consecuencias de tenerlas sentadas mucho tiempo, porque son bien sabidas, y con frecuencia se experimentan en cierto tiempo de la vida; y aunque en este critico periodo sean felices, quedan expuestas a otros riesgos cuando llegan a ser madres; porque las mujeres que se han acostumbrado a hacer una vida sedentaria, generalmente corren mucho riesgo en la procreación, en tanto que las que han hecho suficiente ejercicio rara vez peligran.

Con dificultad se ve una niña, que al mismo tiempo que se precia de la temprana instrucción de la aguja, tenga una buena constitución; el exceso de la aquiescencia ocasiona, 
por lo general, indigestiones, jaqueca, complexiones pálidas, toses, consunción de los pulmones y deformidades de cuerpo, que no se deben extrañar si consideramos la violenta postura que toman para hacer algunas labores" (Bastús, 1861, p. 13).

Por lo tanto, en este juego, las niñas sí que podían sentir la tensión y fantasía del juego, y, también, la posible reprobación si salían de alguna manera lastimadas del lance; y, ahora bien, como sostenía Fonssagrives (1877, p. 132): “Conviene a la solicitud de las madres no dejar que este juego se prolongue hasta un límite tal que el cuerpo se empape en sudor y el corazón lata con impetuosidad". También en palabras de Francisco Fernández Villabrille (1811-1864): "Este juego es propio de los muchachos más las niñas de los colegios salen en corporación y hacen alto en el campo, pueden divertirse con él sin inconvenientes, porque son muchas las que entran y tiene grande animación” (Fernández Villabrille, 1864, p. 44) (Figura 9).

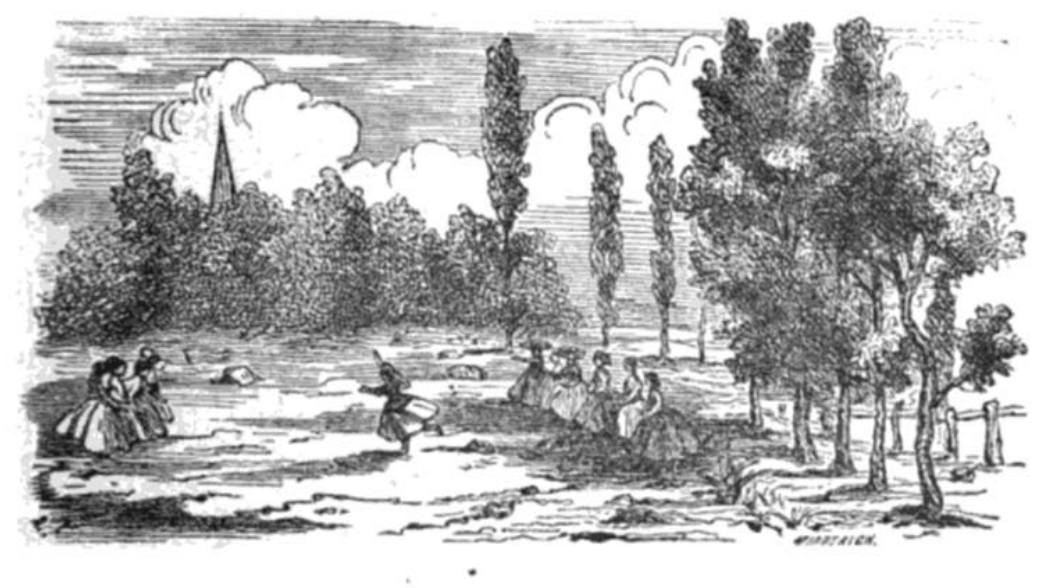

Figura 9. Imagen del juego del marro practicado por las niñas en el campo. Juegos $y$ entretenimientos de las niñas (Fernández Villabrille, 1864)

Y toda esta aparición escolar y emoción del juego del marro surge de manera intensa en los momentos escolares de la época de la renovación pedagógica, como sucedió con el modelo de Vergés (Brasó y Cercós, 2019; Brasó y Torrebadella, 2014). Es en la Escuela del Mar (1921-1938), que dirigió el maestro Pere Vergés i Farrés (1896-1970), cuando el juego del marro entró a formar parte de un proyecto educativo en el marco de la Escuela Nueva. En esta ocasión, el juego era utilizado para compartir valores sociales y educar en democracia. El aprovechamiento didáctico del juego marcó un giro pedagógico al introducirlo en un contexto de coeducación, de cesión de autonomía, pero también de deportivización (Brasó, 2015, 2017; Brasó y Cercós, 2019; Brasó y Torrebadella, 2014).

\section{A MODO DE CONCLUSIÓN}

Sobre lo expuesto hay que insistir en el reflexionar históricamente, es decir, tener en cuenta el pasado, no tan pasado, para entender el presente y atender el futuro. $\mathrm{Y}$, sobre el presente en particular, hay que "recordar que el juego no es una innovación, es un derecho asociado a la libertad de la infancia" (Brasó y Torrebadella, 2017a, p. 547), tal y como consideró la activista Ellen Key (1906, p. 58): “iLos juegos vigilados y dirigidos por el maestro son una verdadera parodia!”. 
En este sentido, el juego del marro entró a formar parte del repertorio lúdico de la infancia. Al ser un juego que no requería de material ni de un espacio concreto, se integró en los momentos de ocio de los más pequeños. Es más, causaba en general gran emoción y reunía grandes cantidades de jugadores y público. Eran momentos para mostrar las habilidades y destrezas de los jugadores, y poder ser reconocidos. Asimismo, esta intensidad lúdica (mal) convivía con los transeúntes que discurrían por estas calles donde se practicaba el marro. Y esta intensidad del juego fue aprovechada por los pedagogos y maestros, a partir del s. XIX, para normativizarlo, y poder inculcar su propia pedagogía. Por ende, se trataban modos de comportamiento o liderazgos, roles... a medida que los pequeños jugaban. Y, al fin y al cabo, este juego albergaba un carácter simbólico, reflejaba la representación social en el grupo y posibilitaba la preparación de lucha por la vida.

Hoy en los centros urbanos de las grandes ciudades del mundo, que llamamos más avanzados y civilizados, los niños y niñas raramente juegan libremente en las calles. El juego libre como tal ya no existe. La ludificación escolar ha aparecido como un virus en la escuela. Todo se ha convertido en un juego, todo se ha gamificado, todo se ha tecnologizado. Sin embargo, en este ambiente escolar, a tales propuestas les falta la esencia del juego: la libertad. Así, se obliga a jugar al alumnado haciendo que la práctica lúdica esté bien dirigida y controlada (Brasó y Torrebadella, 2017a).

Percibimos que la sociedad actual se ha vuelto demasiado peligrosa para la infancia, pero no es cierto, en el pasado los peligros eran mucho mayores. La represión sobre la infancia continúa y el mundo civilizado de los adultos juega con ello y traslada a los menores múltiples violencias -y estas ya no son simbólicas- muy efectivas; el sobreproteccionismo es una de ellas. Así, en la era del turbo-capitalismo la sociedad consumista invade de mensajes de clase ociosa a la infancia. Son mensajes de violencias de todo tipo: de género, de clases, de razas, de culturas, de simple depredación egocéntrica y narcisista; mensajes que hacen de la vida una competición y una ficción, en la que ya no cuenta el juego del marro y, tampoco, aquel héroe -solidario- que se arriesgaba para salvar a sus compañeros.

Y a causa de ello, seguramente, la competición en la escuela se convierte en un tabú, aunque si visualizamos la lógica interna de la disciplina escolar, aparece de forma significativa con las cualificaciones, los comentarios de los docentes o las distribuciones grupales.

Pero una vez más, hay que advertir que los juegos de competición, como han citado muchos autores, pueden utilizarse de forma antagónica con la misma educación (Gutiérrez Delgado, 2004). Por lo tanto, solamente en una estricta con-ciencia intelectual y política podremos comprometernos para re-formular una educación crítica -y una educación física crítica (Brasó y Torrebadella, 2018) - y descolonizadora (Moreno, Toro y Gómez, 2018) que se asiente sobre los derechos fundamentales de la infancia: dejemos de ju(z)gar en la escuela, con la escuela no se juega.

\section{BIBLIOGRAFÍA}

Alba, S. (1899). Prólogo. En E. Demolins, En qué consiste la superioridad de los anglo-sajones (pp. V-CXXX). Madrid: Librería de Victoriano Suárez.

Álvarez, J.S. (dir.) (1902, 23 de agosto). Páginas Infantiles. La payana.- El rescate.-Las plumas. Caras y Caretas, p. 62. 
Amar, J. y Jauffret, L. (1803). La gymnastique de la jeunesse. Paris: A. G. Debray.

Amorós, F. (1848). Nouveau manuel d'éducation physique, gymnastique et morale. Vol. I, II y Atlas. Paris: Librairie Encyclopédique de Roret.

Andújar, I. y Brasó, J. (2017). La lógica interna en Los Juegos de niños (1560) de Peter Brueghel. RICYDE. Revista Internacional de Ciencias de la Actividad Física y el Deporte, 13(50), 426-441. Disponible en: https://doi.org/10.5232/ricyde2017.05008

Arenal, C. (1892). La educación de la mujer. Boletín de la Institución Libre de Enseñanza, 377, 304-312.

Arnal, S. (1893). Los juegos corporales. La Escuela y el Hogar. Revista Pedagógica, 9, 97-99.

Arnal, S. (1897). Paseos escolares. Pamplona: Imp. Provincial.

Ayuntamiento de Barcelona (1857). Ordenanzas municipales de Barcelona. Barcelona: Imp. de Nueva de J. Jepus y R. Villegas.

Bailly-Balliere (1912). Juegos al aire libre... El Marro. En Almanaque Bailly-Balliere (pp. 412413). Madrid: Bailly-Balliere.

Bailly-Balliere (1918). Deportes sencillos e higiénicos... El Marro. En Almanaque Bailly-Balliere (pp. 341). Madrid: Bailly-Balliere.

Bastús, F. (dir.) (1861, 10 de noviembre). Higiene doméstica. Ejercicio de los niños. La Aurora de la Vida, 12-14.

Brasó, J. (2015). Thomas Arnold, Pere Vergés i els jocs organitzats. Els escacs, un projecte educatiu a l'Escola del Mar. Temps d'Educació, 49, 135-163.

Brasó, J. (2016). Los inicios de la mujer en la pràctica del ajedrez en España (1922-1935). Investigaciones feministas, 7(2), 331-355. doi: https://doi.org/10.5209/INFE.51750

Brasó, J. (2017). Historia y Pedagogía de la Escuela del Mar (1922-1938). Estudio icónicohermenéutico. Historia Social y Educación, 6(3), 226-260.

http://dx.doi.org/10.17583/hse.2017.2717

Brasó, J. (2018a). Higienisme, educació i colònies escolars al voltant de 1918. Jornada en Pensament pedagògic avançat: Reflexió sistemàtica. Grup de Recerca en Pensament Pedagògic i Social Contemporani (GREPPS-UB), 4 julio. Institut de Ciències de l'Educació (ICE)

Brasó, J. (2018b). Imatges del present per (re)descobrir el passat pedagògic. El pal·li de Siena i els valors de l'Edat Mitjana. En N. Llevot y J. Sanuy, Educació $i$ desenvolupament rural als segles $X I X-X X-X X I$ (pp. 545-561). Lleida: Universitat de Lleida.

Brasó, J. y Cercós, R. (2019). Pere Vergés Farrés (1896-1970): Un pedagogo de la competición ludicodeportiva. Apunts. Educación Física y Deportes, 137, 11-16. doi:10.5672/apunts.2014-0983.es.(2019/3).137.01

Brasó, J. y Collell, X. (2016). El joc popular de la xarranca. Estudi a través dels llibres i del folklore català. Possibles aplicacions en l'àmbit escolar. REIRE. Revista d'Innovació $i$ Recerca en Educació, 9(2), 82-105.

Brasó, J. y García, J. (2019). Semblances entre l'agogé lacedemònia i l'educació neoliberal actual. Reflexions per una educació crítica. Temps d'Educació, 56, 17-36.

Brasó, J. y Torrebadella, X. (2014). El joc del 'rescat' a Catalunya. Un projecte educatiu a l'Escola del Mar de Pere Vergés. Temps d'Educació, 47, 191-212.

Brasó, J. y Torrebadella, X. (2015a). Anàlisi i classificació dels jocs de la infància de Joan Amades en funció de la seva lògica interna i del gènere dels practicants (1674-1947). REIRE: Revista d'Innovació i Recerca en Educació, 8(2), 18-42

Brasó, J. y Torrebadella, X. (2015b). El joc del 'rescat' en el procés constituent de l'esport contemporani a Catalunya (1900-1926). Aloma: Revista de Psicologia, Ciències de l'Educació i de l'Esport, 33(1), 79-91.

Brasó, J. y Torrebadella, X. (2015c). "El marro", un juego tradicional y popular en la educación física española (1807-1936). Revista Complutense de Educación, 26(3), 697-719. 
Brasó, J. y Torrebadella, X. (2016). Investigación-acción y método de proyectos en educación física: organización de un torneo de marro. Estudios Pedagógicos, 42(2), 21-37.

Brasó, J. y Torrebadella, X. (2017a). ¿Por qué nos hacen jugar en la escuela? Reflexiones pedagógicas para (¿criticar?) entender la enseñanza actual. En R. Mínguez y E. Romero (Coord.), CITE. XIV Congreso de Teoría de la Educación. Murcia 21 y 23 de noviembre de 2017. La educación ante los retos de una nueva ciudadanía (pp. 541-549). Murcia: Universidad de Murcia.

Brasó, J. y Torrebadella, X. (2017b). El juego motor del marro: una indagación acerca de sus raíces pedagógicas. Revista Dialectología y tradiciones Populares, 72(1), doi: 10.3989/rdtp.2017.01.10, 245-264.

Brasó, J. y Torrebadella, X. (2018a). El juego del marro. Un dispositivo de la pedagogía disciplinar en la tradición inventada de la educación física contemporánea del siglo XIX y principios del XX. Lúdica Pedagógica, 1(27), 85-96. Recuperado de: https://revistas.pedagogica.edu.co/index.php/LP/article/view/9443

Brasó, J. y Torrebadella, X. (2018b). Figuras y héroes universitarios. Recordando a Claudio Lozano. En VVAA, La historia de la Educación entre Europa y América. Madrid: Dykinson.

Brasó, J y Torrebadella, X. (2018c). Reflexiones para (re)formular la educación física crítica. Revista Internacional de Medicina y Ciencias de la Actividad Física y el Deporte, 18(71), 441-462. http://dx.doi.org/10.15366/rimcafd2018.71.003

Brasó, J. y Torrebadella, X. (2019a). El juego del marro y la genealogía pedagógica y sociológica del poder disciplinar del deporte. Athenea Digital, 19(3), e2364. https://doi.org/10.5565/rev/athenea.2364

Brasó, J. y Torrebadella, X. (2019b). El juego popular de las cuatro esquinas:30 variantes para recuperar su uso en la educación del siglo XXI. Historia de la Educación, 38, 155-177.

Brasó, J. y Torrebadella, X. (2020). Pedagogías comparadas. De la Escuela del Mar (1922) y Pere Vergés a la Escuela 26 de enero (1943) y Enric Gibert. Revista Española de Educación Comparada, 36, 146-179. doi:10.5944/reec.36.2020.26995

Campan (1845). Tratado de la educación de las niñas, ó sea, Consejos á las madres que desean educar bien a sus hijas. Barcelona: Saurí.

Cortezo, C.M. (1923). Paseos de un solitario. Madrid: Ruiz Hermanos Editores.

Cuenca, C.L. (1901, 27 de septiembre). Entremeses. La Correspondencia Militar, p. 3.

De Genlis [Condesa] (1842). Veladas de la quinta: novelas e historias dedicadas a las madres de familia ( $6^{\mathrm{a}}$ ed.). Barcelona: Saurí.

De Genlis [Condesa] (1864). Las veladas de la quinta: novelas e historias morales para que las madres de familia puedan instruir a sus hijos juntando la doctrina con el recreo. Barcelona: Sociedad Editorial Maravilla.

De Larra, F.J. (1944). Mariano José de Larra (Fígaro): biografia apasionada del doliente de España. Barcelona: Amaltea.

De Marco, L. y Ochoa, E. (1896). Repertorio completo de todos los juegos. Madrid: Lib. Ed. de Bailly-Bailliere e Hijos.

Dillaye, F. (1885). Les jeux de la jeunesse. Paris: Hachette.

Elias, N. y Dunning, E. (1992). Deporte y ocio en el proceso de civilización. Madrid: Fondo de Cultura Económica.

Elschenbroich, D. (1979). El juego de los niños. Madrid: Zero.

Fernández Villabrille, F. (1864). Juegos y entretenimientos de las niñas. Madrid: Mellado.

Fonssagrives, J.B. (1877, 28 de mayo). Pedagogía. Educación física de las niñas. Ejercicios físicos y juegos. Instrucción pública, 131-133.

Francos, J. (1883). ¡Como los hombres! La Madre y el Niño. Revista Ilustrada de Higiene y Educación, 12, 185-186.

Gallach, J. (1915, febrero). El marro. Mi Revista, p. 37. 
García-Fraguas, J.E. (1896). Tratado racional de gimnástica y de los ejercicios y juegos corporales..., t. II Teoría general de la gimnástica y del Sport. Madrid: Casa editorial y Lib. de la Viuda de Hernando y $\mathrm{Ci}^{\mathrm{a}}$.

Gutiérrez Delgado, M. (2004). La bondad del juego, pero... Escuela Abierta, 7, 153-182.

Hughes, T. (1923). Tomás Brown en la Escuela. Madrid: Calpe.

Janet, P. (1870a). Lecciones de Filosofía y Moral. Cuarta lección. El padre y la madre. Boletín del Ateneo de Valencia, 1(10), 298-306.

Janet, P. (1870b). Lecciones de Filosofía y Moral. Sexta lección. El hijo. Boletín del Ateneo de Valencia, 1(14), 426-432.

Jueves y Domingos (1874, 21 de junio). El Mundo Cómico, p. 2.

Key, E. (1906). El siglo de los niños. Tomo I. Barcelona: Herich y Ca.

Le Prince, X. (1822). Les Jeux des Jeunes Garçons... Paris: Chez Nepveu.

Llaverías, A. (1904, 29 de octubre). A vuela pluma. Los Deportes, p. 684.

Llorens, M. y Torrebadella, X. (2017). La gimnástica o escuela de la juventud (1807): primer libro de educación física escolar y génesis de un discurso pedagógico. Revista de Investigación en Educación, 15(2), 122-139. Recuperado de:

http://reined.webs.uvigo.es/ojs/index.php/reined/article/view/1430

López Villabrille, F. (1855). Recreo de la Infancia. Colección de juegos para niños. Madrid: Antonio Pérez Dubrull.

Marín Perujo, A. (1883). Los niños revoltosos. La Madre y el Niño. Revista Ilustrada de Higiene y Educación, 8, 118-119.

Moreno, A., Toro, S. y Gómez, F. (2018). Crítica de la educación física crítica: eurocentrismo pedagógico y limitaciones epistemológicas. Psychology, Society \& Education, 10(3), 349362.

Naharro, V. (1818). Descripción de los juegos de infancia, los más propios a desenvolver sus facultades fisicas, morales, y para servir de abecedario gimnástico. Madrid: Imp. que fue de Fuentenebro.

Ossorio, M. (1888, 30 de julio). Romances infantiles. El Marro. El Mundo de los Niños, 323-324.

Pereda, J.M. (1880, 14 de enero). Las tres infancias. La Ilustración Católica, 207-211.

Pereda, J.M. (1888). Esbozos y rasguños. Madrid: Imp. de Manuel Tello.

Pujadas, A. (1848, 4 de julio). El Domingo. Paseo Nuevo. El Barcelonés, p. 1.

Ramón y Cajal, S. (1925). Cuando yo era niño: la infancia de Ramón y Cajal / contada por él mismo ( $3^{\mathrm{a}}$ ed.). Madrid: Reus.

Rodríguez, B. [De la revista Calasancia] (1919). La piedad de nuestro Ministerio escolar. El juego principal ocupación de los niños. La Escuela Moderna, 336, 684-692.

Sánchez-Crespo, D. (2010). Micromundos: Daniel Sánchez-Crespo at TEDxBarcelona. Disponible en: https://www.youtube.com/watch? $v=G x X k$-vqqTPI [consulta el 21 de julio de 2020]

Serra, A. (1905, 3 de abril). La cultura física en nuestro siglo. La Vanguardia, p. 1.

Sport Popular (1893, 1 de abril). Crónica del Sport, p. 112.

Torrebadella, X. (2011). Vicente Naharro y los juegos corporales en la educación física española de la primera mitad del siglo XIX. Ágora para la Educación Física, 13(2), 165-182.

Torrebadella, X. (2015). Los batallones infantiles en la educación física española (1890-1931). ODEP. Revista Observatorio del Deporte, 1(1), 32-70.

Torrebadella, X. (2017). La militarización de la educación física escolar. Análisis de dos imágenes publicadas en la prensa de Barcelona de principios del siglo XX. Historia Social $y$ de la Educación, 6(1), 78-108. doi:10.17583/hse.2017.2393

Torrebadella, X. y Brasó, J. (2014). El juego del marro: Análisis de la lógica interna y posibilidades educativas. Tándem. Didáctica de La Educación Física, 45, 75-79. 
Torrebadella, X. y Brasó, J. (2019). Los juegos corporales en la educación física del siglo XIX como preludio al deporte moderno en España. Ciencia, Cultura y Deporte, 14(41), 165 177. http://dx.doi.org/10.12800/ccd.v14i41.1276

Torrebadella-Flix, X. y Domínguez, J.A. (2018). Las escuelas gimnásticas en España: un enfrentamiento técnico doctrinal en la educación física (1806-1936). Materiales para la Historia del Deporte, 17, 136-165.

Un aficionado (1903). Bailes y juegos: diversiones varias para entretenimiento y recreo de las tertulias y sociedades... Madrid: Hijos de D. J. Cuesta.

Vega-Rey, L. (1884). Los niños en los talleres. La Madre y el Niño. Revista Ilustrada de Higiene y Educación, 13, 104-105.

Vega-Rey, L. (1885). Pobreza y mendicidad. Madrid: Imp. Enrique Teodoro.

Vergnaud, P. (1831). Manuel des jeunes gens ou sciencies arts de la recreation. Paris: Librairie Encyclopédique de Roret. 